\title{
Diversity of Learners: A Study about how Individual Differences Affect the L2 Learning Process
}

\author{
John Ramil A. Valle ${ }^{1} \square$ Ramil G. Ilustre ${ }^{2}$, Donna May R. Figuracion ${ }^{3}$, Larme M. Cabahug ${ }^{4}$, Rosario R. \\ Paningbatan ${ }^{5}$, Karlyn Cherlot C. Guerrero ${ }^{6}$ and Maria Joanna E. Amparo ${ }^{7}$ \\ ${ }^{1}$ Tondo High School, Manila, Philippines \\ ${ }^{2}$ Professional Lecturer of English, Bulacan State University, City of Malolos, Philippines \\ ${ }^{3}$ Sacred Heart Academy of Novaliches, Quezon City, Philippines \\ ${ }^{4}$ Dona Rosario High School, Quezon City, Philippines \\ 5 Libtong Elementary School, Meycauayan City, Philippines \\ ${ }^{6}$ College of Mary Immaculate, Pandi, Bulacan, Philippines \\ ${ }^{7}$ Systems Plus Computer College, Caloocan City, Philippines
}

$\square$ Corresponding Author: John Ramil A. Valle, E-mail: johnramil.valle@bulsu.edu.ph

\begin{tabular}{ll}
\hline ARTICLE INFORMATION & ABSTRACT \\
\hline $\begin{array}{l}\text { Received: } 08 \text { October } 2021 \\
\text { Accepted: } 25 \text { November } 2021\end{array}$ & $\begin{array}{l}\text { Individual differences are considered one of the main factors in language learning. This } \\
\text { article begins by presenting the definition of individual differences and identifying the } \\
\text { Published: } 08 \text { December } 2021\end{array}$ \\
pol: $10.32996 / j w e e p .2021 .3 .12 .1$ & $\begin{array}{l}\text { the literature review, shows that there are eight (8) major individual differences to be } \\
\text { found as salient features in the L2 learning process. A brief overview of these eight (8) } \\
\text { individual differences is provided, supported by the literature review of } 20 \text { journal }\end{array}$ \\
\hline KEYWORDS & $\begin{array}{l}\text { articles. This journal article used grounded theory design as a method in identifying } \\
\text { the relationship of the following individual differences in the L2 learning process. }\end{array}$ \\
$\begin{array}{l}\text { L2 Learning Process, Individual } \\
\text { Differences, Limited English }\end{array}$ & $\begin{array}{l}\text { According to the results, although there is a growth in the study of individual } \\
\text { differences that affects the L2 learning process, there is still much work to be done and } \\
\text { much more investigation is required. }\end{array}$
\end{tabular}

\section{Introduction}

Early research in language learning inclined with establishing the general principles that could be applied in a broad spectrum of individual differences and contexts (e.g., Chomsky's universal grammar, Lenneberg's critical period hypothesis, Krashen's five hypotheses, Pieneman's teachability hypotheses, Schumann's acculturation model.) Individual differences can be defined as personal characteristics that distinguish learners from each other in the teaching and learning processes (Duff, 2017). Learners are unique individuals who bring a critical set of variables to each learning situation, including delicate traits as indicators of their potential and the history of achievement as signs of previous accomplishments and predictors of future performance (WenTa Tseng and Xuesong Gao, 2021). The following models tend to explain the overall body of knowledge about how a language can be learned through the L2 learning process, but they tended to overlook the basic facts that each of the learners is diverse to each other. Hence learners' ability to learn another/target language varies depending on their differences.

Many factors can influence the L2 learning process. Selinker (2019) stated about individual differences in language learning that "a theory of language learning that does not provide a central place for individual differences among learners cannot be considered acceptable." After that, Wong Filmore observed: "Anyone who works with ... language learners, whether in teaching or research, discovers quickly how much individual variation there is." Lastly, Skehan's influential book on individual differences appeared and generated the statement "veritable plethora of individual learners' variables which researchers have identified as influencing learning outcomes." As we progressed into the new century, learning a new language became popular and gave more

Copyright: (c) 2021 the Author(s). This article is an open access article distributed under the terms and conditions of the Creative Commons Attribution (CC-BY) 4.0 license (https://creativecommons.org/licenses/by/4.0/). Published by Al-Kindi Centre for Research and Development, London, United Kingdom. 
opportunities for cooperation between countries and communication between people all over the world, as a result of which many people, other than students, are eager to learn a second language, featuring the learning of English (Yuefang Sun, 2019).

In the past few years, several special issues on individual differences (IDs) in language learning have been published in the field of language education which contribute to the L2 learning process. One of the deals with the subject at length was Carol Griffiths and Adem Soruc, who listed age, sex, motivation, beliefs, personality, culture, and learning style. These individual differences greatly affect the $\mathrm{L} 2$ learning process, wherein characteristics that make learners different from each other and which affect the way that they behave in the classroom and beyond.

\section{Literature Review}

Individual differences have been central to human psychology in view that the early 20th century, lookup on non-human animals has, till recently, tended to pass by the variant amongst individuals. Over the closing decade, there has been a growing center of attention on the intraspecific variant in non-human animals. This is perhaps influenced by the behavioral ecology strategy originating in the 1980s, which explicitly considered herbal selection on individual phenotypes; the extra current research of animal personality, which emphasize man or woman differences across correlated suites of behaviors; the improvement of statistical (mixed) modeling strategies that permit explicit consideration of character differences; and the improvement of science permitting fine-scale monitoring of individuals' actions and interactions. This exclusive difficulty attracts collectively recent theoretical and empirical developments in the rising subject of individual differences in cognition. (Neeltje J. Boogert, Joah R. Madden, Julie Morand-Ferron, and Alex Thornton, 2018)

What individual differences should be included that may affect the L2 learning process? This question paved the way for the discussion on the list of individual differences that should be included on the list that affect the L2 learning process. A review of the literature reveals that, even among those who are considered experts and who have published on the subject, the consensus is far from absolute regarding what should be included as an individual difference.

As experienced language teachers who have had to deal with individual differences in their classrooms, Griffiths and Soruc (2021) included 8 individual factors which they have found contribute to learners' individuality:

\subsection{Age}

Age is frequently associated with a decline in cognitive skills that are important for retaining useful independence, such as gaining knowledge of a new language. Many forms of gaining knowledge of a language show up to be properly preserved with age while gaining knowledge of duties that involve associative binding has a tendency to be negatively affected. The necessary length hypothesis tended to dominate the questioning on the question of age in language learning for quite a lengthy time. More recent research, however, has tended to render assumptions made on the foundation of this hypothesis open to doubt, seeing that numerous research has proven that mature newcomers are capable of learning a language very effectively (Birdsong, 2018). Despite the evidence from these studies, English continues to be promoted around the world at younger and younger a long time in the faith that younger is better. As Griffiths and Soruç point out, there may be numerous motives because adults may additionally fail to research the language as successfully as children, including motivation, identity, ecological/contextual issues, personal circumstances, family/employment demands, time, and social constraints, and individual characteristics. These elements interact in complex and dynamic approaches to affect the outcome of attempts to examine the language, which includes limiting exposure to the language and the time and power available. Despite constraints, however, there are numerous examples of adults who do manipulate to learn a new language very efficiently (as noted above), setting in serious doubt the existence of the previously hypothesized critical period, at least as some inflexible and impenetrable barrier.

\subsection{Sex}

Sex refers to either of the main categories (male and female) into which humans and most other living things are divided based on their reproductive functions. Females are often believed to be higher language learners than males, although proof to affirm this belief has been elusive. There is some evidence that ladies have extra nerve cells in the left half of the talent the place language is centered, and, in addition, females regularly appear to use both aspects of the brain; regular proof for this, however, is additionally inconclusive, although neurological research is gaining momentum as the science develops. Where differences in accordance to sex/gender are in evidence, they can also well be due as a lot to the complicated and dynamic interaction with different elements such as motivation, investment, goal-orientation, socialization, non-public circumstances, family expectations, and socio-ecological context, and so on. As Nyikos factors out, man or woman differences in language studying according to sex/gender tend to be mild to nonexistent, with a way higher variation between men and women than between the sexes. Sunderland, consequently, factors out that it is essential to keep away from "oversimplification and unproductive generalizations" along sex/gender lines. Research effects to date tend to indicate that, given the right conditions, encouraged men and females can analyze language successfully equal. 
Within the context of the United States, statistical research proves the gender gap in SLA, as well as an ethnic gap in SLA. According to the 2013 Census, Limited English Proficiency (LEP) records are best regarding the age group 18-64, and Latinx immigrants make up $63 \%$ of the LEP population. About the service occupation, the occupation with the absolute best percentage of LEP workers, $45 \%$ of women within the subject are LEP, while solely $25 \%$ of guys are LEP. This disparity also carries over into the fields of sales and office occupations. Through the Peters 62013 Census, it is obvious that a gender gap and ethnic gap are present within the context of SLA in the United States. (Cheyenne Paters, 2019)

\subsection{Motivation}

Motivation has been proven to be perhaps the most important thing in successful language mastering. Traditionally, motivation has been perceived as dichotomous: intrinsic versus extrinsic and instrumental versus integrative. Over the years, claims have been made that one or different of these motivational kinds is the most important for successful language learning, but motivation is complex, and all of these motivational kinds might also have a section to play in consequence of language learning endeavors. Not solely that, however, motivation is dynamic; that is, it can change, so just because a learner is or is no longer encouraged at one point in time (Jamilah Mohammed Sadiq, 2017), this the motivational level can fluctuate according to other individual factors, variants in the background of the learner's lifestyles (e.g., job, family, health), ecological changes, changes in goal-orientation, or interplay with different individuals. All of these variables may affect a learner's willingness to invest time and effort in the language learning endeavor. If the will to proceed investing starts of evolving to fade in the face of difficulties, learners may also need to engage their motivational self-system or utilize volitionally strategies, which are undertaken to assist the learner to persevere in the face of difficulties to hold motivation (Adnan Oflaz, 2019). Of course, some of these personal variations may be regarded to be essentially specific from others. Age, sex, and race, for instance, are biological, whilst others are socio-cultural and/or ecological (especially nationality and culture), while others (perhaps the majority) are psychological. Nevertheless, as any teacher knows, all of these elements can have interacted with each other in complex methods to affect lecture room dynamics, and for this reason, they deserve to be included when considering the function of individual differences in language development.

\subsection{Beliefs}

The impact of beliefs on language getting to know used to be first delivered to huge interest by Elaine Horwitz, who produced the Beliefs about Language Learning Inventory or BALLI, which has been used in much research in the years since. Beliefs would possibly be defined as something which a character holds to be true, such as "I have no aptitude for language" and "I am too old to examine the language" (Griffiths, 2021). Beliefs have the potential to profoundly have an impact on the effectiveness of language learning, and they are formed in part using the complex interplay of learners' very own character characteristics and the cultural norms and expectations into which they were born and/or in which they operate. Although beliefs are regularly assumed to be a relatively secure person characteristic, there is some proof that they are dynamic and that excellent language learners are successful in adapting their beliefs to maximize the affordances of specific learning situations and opportunities. From an ecological perspective, Peng discovered that beliefs about language studying "are issue to contextual mediation", and an interesting exchange in learner beliefs is said with the aid of Kaypak and Ortaçtepe, who discovered that individuals shifted their focus from accuracy to intelligibility at some point of an overseas study journey.

\subsection{Personality}

According to Feist and Feist (2020), personality is a sample of permanent characteristics and special traits that give both consistency and individuality to a person's behavior. Traits contribute to character variations in behavior, consistency of behavior over time, and behavior balance throughout situations. Eysenck (2019) pointed character is the real or plausible conduct patterns of the organism, as determined by heredity and environment. It originates and develops thru the 4 important sectors' practical interplay into which these behavior patterns are organized: intelligence, character, temperament, and constitution. Eysenck's idea has a greater famous notion than other theories about extrovert and introvert personality. According to Eysenck (2019), there are seven aspects of the extrovert, an introvert character such activity, sociability, risk-taking, impulsiveness, reflectiveness, expressiveness, and responsibility.

If we add personality to this already complicated and dynamic mix, we discover that our individual is starting to look more and more multifaceted. Personality has historically been viewed as an extraordinarily steady man or woman characteristic that develops at a younger age and stays reasonably regular at some stage in an individual's life (Warda, Rahman, and Jabu, 2020). The latest research, however, has tended to support the thought that personality may also not be set in stone, but that it may additionally boost dynamically in accord with other changes in an individual's life or environment. A component of persona that is often believed to influence language gaining knowledge of is the introversion/extroversion dimension, which features in many of the customary character checks (e.g., the Myers-Briggs Type Indicator or MBTI). Since extroverts seem to exhibit the strongest want to communicate, they are often assumed to be higher language novices than introverts; there is research, however, which suggests that this assumption might also no longer be well-founded. Other factors of persona often covered in lookup consist of willingness 
to communicate and ego permeability (Kustati, 2019). However, though the character may additionally be a salient characteristic in a classroom, there seems to be little evidence of a relationship between personality and profitable language learning.

\subsection{Culture}

There has been a discussion about the complicated function of lifestyle in language learning: Is it viable for one to analyze a language except getting to know about its cultural aspects? Is it feasible to "teach" tradition at all? If a teacher believes in the "teaching" way of life in tandem with the language, what does the trainer suggest using "culture"? Does teaching tradition certainly imply introducing some factors of surface lifestyle such as customs, food, or festivals, or does it suggest elevating the awareness of students in the direction of the deeper way of life such as beliefs, values, and/or norms that are manifested in people's behaviors? Furthermore, which "cultures" must be chosen to be consultants of the way of life for the language? The list of questions seems to be endless and the catch 22 situation worried insolvable. However, it looks that people agree to at least one imperative premise: Culture is now not only inseparably related to language but also performs a vital function in the course of the procedure of language educating and learning (Griffiths, 2021). But it is also possible for an individual to belong to different categories: in New Zealand, for instance, there is a large group of people with NZ nationality who are racially and ethnically Chinese and who adhere to varying degrees to Chinese culture (e.g., their dress codes, festivals, and family occasions such as weddings). The query is no longer whether or not to teach culture, but, rather, what kind of educating can promote students' grasp of the nature of the language, communication, and human relations. Tucker and Lambert (2018) referred to that the potential to communicate thoroughly in a second language depends on the degree of non-ethnocentrism of the learner. The successful learner should increase "a cognizance of and sensitivity toward the values and traditions of the people whose language is being studied" (Duff, 2017). The significance of an appreciation of the "culture" in which the target language is spoken for college students of an overseas language has emerged as clear. Here, I have to come back to the questions raised earlier; what do human beings suggest using "culture"? In an overseas language classroom, when instructors discuss incorporating a way of life into language teaching, it often capacity simply introducing ordinary customs or traditions of the given 4 societies. For example, in a Japanese language class, an instructor may additionally introduce some Japanese customs or social rules such as when you get hold of a present, do not open it in front of the giver but alternatively simply put it aside, or they devour uncooked fish, and so on. These are, of course, part of Japanese culture, and may also be useful to comprehend when touring a Japanese home. Yet, it does now not explain the reasons or beliefs in the back of all these social behaviors to which one should be added to recognize Japanese culture. Usually, in this sort of instruction, differences or peculiarities tend to be emphasized and stereotypes created.

\subsection{Learning Style}

Learning style is occasionally believed to be a component of personality, and some of the factors overlap. Learning fashion is commonly defined in phrases of a learner's preferred way of learning, and over the years, there have been numerous gadgets developed in attempts to measure it, such as Reid's Perceptual Learning Style Preference Questionnaire (PLSPQ), which was the first generic questionnaire developed specifically for language learning. Based on the report, students are divided into different learning styles (listening, writing, structure, and reading). There are some ways used by the students to get, process, and recall information efficiently and effectively. For instance, some can remember new vocabulary easily by using pictures. Some others prefer learning by song, the rest like learning by games or even other ways. These phenomena require the teacher to apply appropriate techniques according to students' learning styles, to help in the L2 learning process. Some techniques can be applied to help students in the L2 learning process for example by using figures, gestures, actions, pictures, drawings, descriptions, synonyms and opposites, defining contexts, and translating. Simply, those techniques can be divided into two technique classifications which are visual and verbal memorizing techniques. Learners with verbal learning styles on speaking have better progress in the L2 learning process than other students (Lingce, 2020). Shatz (2019) stated that learners could be quite awesome from every other in they're getting to know the style, which can present troubles in a study room environment (e.g., where students who like to work quietly on their personal need to attempt to pay attention to their work among kinesthetic inexperienced persons who desire to go round and interact), and excellent learners seem to be greater successful than much less successful newbies of style-stretching to go well with a given learning state of affairs. However, as Nel observes, there does not appear to be anyone style that is standard of excellent language rookies or which seems greater probable than any different to lead to success. Factors that are frequently covered under learning fashion and which engage in shaping a complex and dynamic relationship encompass cognitive style, in/ tolerance of ambiguity, risk-taking, and discipline independence.

\subsection{Autonomy}

Strategies have long been viewed as an integral device for creating learners' autonomy or the ability to manage or manipulate their learning. Autonomous beginners are capable of making decisions about their learning, which take account of the complexities of the mastering situation, the studying goal, and their very own man or woman desires and characteristics (Griffiths 2021). Autonomy is dynamic; that is, it develops in accordance with elements such as learner identification and organization (i.e., the capability to take action) and helps to strengthen metacognition (i.e., the potential to suppose about wondering and manipulate the getting to know the process) and self-regulation. Although autonomy is regularly presumed to be a solitary and self-absorbed 
process, effective autonomy includes the learners' capability to negotiate and have to interact socio-culturally with others. Recent books about managing sources for self-sufficient learning, fostering learner autonomy, and proposing new lookup agendas attest to the ongoing hobby in the autonomy phenomenon.

\section{Methodology}

This study is based on a qualitative grounded theory design. The grounded theory design method focuses on collecting and analyzing data to develop a substantive theory/data and reading the literature review to explain the findings. With recent popularity, national research has devoted sessions and papers to it, and educational journals have published articles reported by teachers, students, and other educators.

This research design which is a type of non-experimental study tries to determine if the gathered data affects the $\mathrm{L} 2$ learning process.

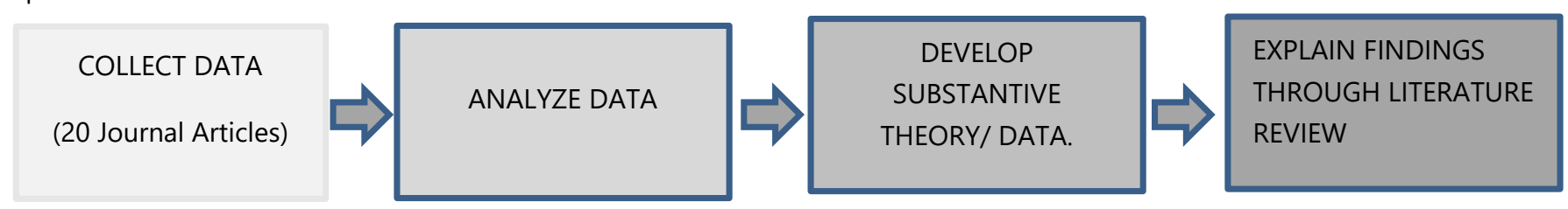

\section{Results and Discussion}

Although some studies may explain the variations observed between individuals in their L2 learning process, a growing number of studies have now provided evidence for consistent inter-individual variation in the L2 learning process. However, the exact mechanisms underlying individual differences in language acquisition are not yet well understood in any field.

Based on the question "What individual differences should be included that may affect the L2 learning process," a review of the literature reveals that there are eight (8) individual factors that have been found to learner's individuality that may affect the $L 2$ learning process: Age, Sex, Motivation, Beliefs, Personality, Culture, Learning Style and Autonomy.

Here are the findings for each of the individual differences that affect the L2 learning process:

4.1 Age is one of the factors that may affect the L2 learning process. In recent studies, adult language learners are more capable of learning a new language rather than youngsters. However, there is also a study that there are external factors that may affect the L2 learning process of the adult language learners like motivation, identity, ecological/contextual issues, personal circumstances, family/employment demands, time, and social constraints, and individual characteristics. Hence, given the situation of adult learners, younger language learners tend to be more successful in the L2 learning process.

4.2 Sex refers to a biological characteristic (male/female) which are the main participant in the L2 learning process, regardless of gender (socio-culturally ascribed as masculine and feminine). Based on the study, females are better language learners than males, because of the evidence that women have more nerve cells in the left half of the brain where language is centered. Also, women often appear to use both sides of their brains. However, if certain sex (male/female) is exposed to too much complex and dynamic interaction with other factors such as motivation, investment, goal-orientation, socialization, personal circumstances, family expectations, and socio-ecological context, etc., the result of the $\mathrm{L} 2$ learning process might be different and language learning with accordance to sex tend to be slightly non-existent.

4.3 Motivation has been proven to be the most important thing in the $L 2$ learning process. If a learner is highly motivated to learn the target language, hence, the L2 learning process will be successful. However, motivation is complex and dynamic, wherein it may be affected by variants in the background of the learner's lifestyle. The motivational level may fluctuate according to individual factors like ecological changes, changes in goal orientation, or interplay with different individuals. All these factors may affect the learner's willingness to spend time and effort in learning a new language, which may affect the L2 learning process.

4.4 Beliefs to be found as a potential to profoundly have an impact on the L2 learning process. If a learner tends to have a positive belief regarding learning a new language, hence, the $\mathrm{L} 2$ learning process will be smooth. Belief is also regularly assumed as a secured personal characteristic but based on the study, belief tends to be dynamic and sometimes learners may adopt other beliefs along the L2 learning process, which will make the result shift to any other possible outcomes.

4.5 Personality is considered a permanent characteristic and special trait that give both consistency and individuality to a person's behavior. The study found out that there are two types of personality, introvert and extrovert. Based on this study of MBTI, extroverts are more efficient in language learning because they exhibit the strongest will to communicate. However, there is little evidence of the relationship between personality and profitable language learning. 
4.6 Culture is considered one of the most complicated functions in individual differences. Culture tends to showcase many aspects in a life of a person like food, festival, beliefs, values, and norms. Which is highly recognized in language learning. Based on the study, culture is not inseparably related to language but also performs a vital function in the course of the L2 learning process. It is also suggested that the learner should increase his/her cognizance of sensitivity toward the culture of the target language.

4.7 Learning style is believed to be a component of personality and some factors overlap. The findings of the present study showed that students with different learning styles in four skills (listening, writing, structure, and reading) differed from each other. So, students with verbal learning style on speaking are better than another student, the student with verbal learning style have good progress in writing from another student, the student with social learning style have good progress in structure from other students, and then, students with verbal and social learning style have high progress in reading from other students. But based on another study, there is no to be anyone style that is standard for excellent language learning. Other factors may still disturb the L2 learning process.

4.8 Autonomy is stated to be the capacity of a learner to act in accordance with his/her objective rather than under influenced desires. The study believed that autonomous beginners are capable of making a decision about their learning which helps the L2 learning process. Also, it found out that autonomy is dynamic and may be affected by learner's identification and organization which will lead to different possible outcomes in the L2 learning process.

\section{Conclusion}

This journal article started by defining individual differences as a variable that affects the $\mathrm{L} 2$ learning process is. Based on the question "what individual differences should be included that may affect the L2 learning process?" literature review shows that there are eight (8) major individual differences that may affect the L2 learning process, namely, age, sex, motivation, beliefs, personality, culture, learning style, and autonomy.

Based on the review of literature, when it comes to age, adult language learners are more capable of learning a new language which will result in a smooth $L 2$ learning process. However, external factors may appear to change the result of the expected outcome. Hence, younger learners will be more superior in the L2 learning process. In terms of sex, the study found out that women tend to be a higher language learner than males. But given the right conditions, encouraged men and women can analyze language successfully equal. While under motivation, highly motivated students tend to have a lesser problem in the L2 learning process, but there are still external factors that may fluctuate the result of the expected outcome. For the beliefs, it shows that it has a potential impact on the L2 learning process. If a learner becomes positive in his/her belief in learning a language, he or she would learn the target language. Personality, on the other hand, is considered a permanent characteristic, which helps a learner in the L2 learning process. However, there is little evidence in the study of the relationship between personality and language learning. Accordingly, Culture is considered as the most complicated as it discusses more external factors among all, but culture is expected to be connected in language learning because it performs a vital function in the L2 learning process. Meanwhile, learning style is believed to be a component of personality. Although there are different learning styles, there is no exact learning style for excellent language learning. Lastly, autonomy is the capacity of learners to act with his/her objective. It shows that autonomous beginners are more capable of making decisions about their $L 2$ learning process, but still, an external factor may arise and affect the outcome of the L2 learning process.

To conclude, although the body of knowledge on individual differences in language learning has grown in recent years, there is still much work to be done. Many individual variations are still understudied; in particular, the significance of aptitude is troublesome, and personality research is unexpectedly hard to come by. Furthermore, to derive meaningful implications for the promotion of successful language learning for our infinitely variable and multifaceted learners in widely varying contexts, the complex and dynamic interaction between and among the various individual factors, as well as with the socio-ecological context, much more investigation is required.

\section{References}

[1] Birdsong D. (2018) Plasticity, Variability \& Age in Second Language Acquisition and Bilingualism. Front. Psychol. 9(81). https://doi.org/10.3389/fpsyg.2018.00081

[2] Boogert, N.J., Madden, J.R, Morand-Ferron J., \& Thornton A. (2018) Measuring and understanding individual differences in cognition. Philosophical Transactions B, 373 (1749). https://doi.org/10.1098/rstb.2017.0280

[3] Dalu, DL.R., Setyawati H., Arianto, M.A., Azizaturrohmah, N. (2016) Availability of Language Input, Conducive Environment in Learning Language and Motivation and its Relation to Language Acquisition. Linguistic, Literature and Language Teaching, 6(1). http://dx.doi.org/10.18592/let.v6i1.1445

[4] Duff, P.A. (2019) Social Dimensions and Processes in Second Language Acquisition: Multilingual Socialization in Transnational Contexts. The Modern Language Journal, 103(1), https://doi.org/10.1111/modl.12534 
[5] Griffiths, C., \& Soruc A. (2021) Individual Difference in Language Learning and Teaching: A Complex/ Dynamic/ Socio-Ecological/ Holistic View. English Teaching and Learning, 45, 339-353. https://doi.org/10.1007\%2Fs42321-021-00085-3

[6] Gonzales, J.X. (2017). Learning Strategies in Second Language Acquisition. US-China Foreign Language, 15(8), $479-492$. https://doi.org/10.17265/1539-8080/2017.08.001

[7] Kustati, M., \& Yusuf Y. O. (2020) EFL Teacher's Attitude towards Language Learners: A Case of Multicultural Classrooms. International Journal of Instruction, 13(1), 353-370.

[8] Lingce, S., Hati, G. M., Damayanti I. (2020) The Effect of Learning Style-based Strategy on Students' Vocabulary Development. Proceeding of $1^{\text {st }}$ International Conference on The Teaching of English and Literature, 1(1), 125-132.

[9] Mohammed, I.B. (2020). Learners Differences in Second Language Acquisition. Journal of Tikrit University for Humanities, 27(9), 43-55. http://dx.doi.org/10.25130/hum.v27i9

[10] Oflaz, A. (2019) The Effects of Anxiety, Shyness and Language Learning Strategies on Speaking Skills and Academic Achievement. European Journal of Educational Research, 8(9), 999-1011. https://doi:10.12973/eu-jer.8.4.999

[11] Peters, C. (2019). Analyzing the Gender Gap in Second Language Acquisition: A New ESL Curriculum for Latina English Learners. Chancellor's Honors Program Projects.

[12] Passiatore, Y., Prichio, S., Oliva, C., \& Carrus, G. (2020) Self-efficacy and Anxiety in Learning English as a Foreign Language: Singing in Class Helps Speaking Performance. Educational, Cultural and Psychological Studies, 20, 121-138. https://doi.org/10.7358/ecps-2019-020-passi

[13] Raheem, K.J. (2014). The Use of First Language in the Second-Language Classroom: A Support for Second Language Acquisition. Gist Education and Learning Research Journal, 9, 55-56. https://doi.org/10.26817/16925777.143

[14] Shatz, I. ( 2016) Native Language Influence During Second Language Acquisition: A Large-Scale Learner Corpus Analysis. Research Gate. https://www.researchgate.net/publication/319968915 Native Language Influence During Second Language Acquisition A LargeScale Learner Corpus Analysis

[15] Sadiq J.M. (2017) Anxiety in English Language Learning: A Case Study of English Language Learners in Saudi Arabia. English Language Teaching, 10(7), 1-7. http://doi.org/10.5539/elt.v10n7p1

[16] Sun, Y.F. (2019) An Analysis on the Factors Affecting Second Language Acquisition and Its Implications for Teaching and Learning. Journal of Language and Research, 10(5), 1018-1022. http://dx.doi.org/10.17507/jltr.1005.14

[17] Tseng, W.T., \& Gao, X.S. (2021) Individual Differences in Second Language Learning: The Road Ahead. English Teaching and Learning, 45, 237-244. https://doi.org/10.1007/s42321-021-00097-z

[18] Warda, R.D., Rahman, A., \& Jabu, B. (2021) The Effects of Students' Personality and Motivation on English Learning Achievement at SMA Negeri 12 Makassar. Eprints. http://eprints.unm.ac.id/20487/1/Journal-Rodiah\%20Nahdatul\%20Warda-191052501083.pdf

[19] Yu, R. M. (2020). Culture in Second or Foreign Language Acquisition. Journal of Language Teaching and Research, 11(6), $943-947$. http://dx.doi.org/10.17507/jltr.1106.10

[20] Yaghoubi-Notash, P.A., \& Khalil, I A. (2017) An Investigation of the Learning Strategies as Bias Factors in Second Language Cloze Tests. Advances in Language and Literacy Studies, 8(2), 92-100. http://dx.doi.org/10.7575/aiac.alls.v.8n.2p.91 